\title{
Effect of gold alloying on stability of silver nanoparticles and control of silver ion release from vapor-deposited Ag-Au/polytetrafluoroethylene nanocomposites
}

\author{
N. Alissawi • V. Zaporojtchenko $\cdot$ T. Strunskus \\ I. Kocabas - V. S. K. Chakravadhanula • L. Kienle • \\ D. Garbe-Schönberg • F. Faupel \\ Published online: 17 November 2012 \\ (C) The Author(s) 2012. This article is published with open access at SpringerLink.com
}

\begin{abstract}
In the present study, nanocomposites containing $\mathrm{Ag}-\mathrm{Au}$ alloy nanoparticle ensembles with various compositions on polytetrafluoroethylene were prepared by physical vapor deposition. After a certain time of immersion of the samples in water, oxidation and dissolution of the Ag nanoparticles (AgNPs) occurred, and changes in the morphology, optical properties and composition of the nanocomposites were examined using transmission electron microscopy, ultraviolet-visible spectroscopy and X-ray photoelectron spectroscopy (XPS), respectively. The composition-dependence and the time-dependence of the silver ion release were studied, and the concentration of the silver ions in water was detected using inductively coupled plasma mass spectrometry. The results indicate that with increasing gold fraction in the $\mathrm{Au}-$
\end{abstract}

N. Alissawi • V. Zaporojtchenko • T. Strunskus • I. Kocabas •

F. Faupel $(\triangle)$

Institute for Materials Science, Multicomponent Materials, Faculty of Engineering, Christian-Albrechts-University (CAU) Kiel, Kiel, Germany

e-mail: ff@tf.uni-kiel.de

V. S. K. Chakravadhanula • L. Kienle

Institute for Materials Science, Synthesis and Real Structure,

Faculty of Engineering,

Christian-Albrechts-University (CAU) Kiel,

Kaiser Str. 2,

24143 Kiel, Germany

D. Garbe-Schönberg

Institute of Geosciences/ICP-MS Lab, Christian-Albrechts-University (CAU) Kiel,

Ludewig-Meyn-Str. 10,

24118 Kiel, Germany

V. S. K. Chakravadhanula

Helmholtz Institute Ulm (HIU) Electrochemical energy storage,

Karlsruhe Institute of Technology (KIT),

Albert-Einstein-Allee 11,

89081, Ulm, Germany
Ag alloy nanoparticles, a strong improvement of the oxidation resistance of the AgNPs occurs. The dissolution of Ag is rapid at the first contact of the sample with water until a saturation state is reached. XPS synchrotron measurements with different excitation energies show that the depletion of $\mathrm{Ag}$ from the nanoparticles does not lead to the formation of a Au-rich shell and that the atomic mobility is high enough in the small nanoparticles of about $5 \mathrm{~nm}$ average size to equilibrate any concentration gradient.

Keywords $\mathrm{Au}-\mathrm{Ag}$ alloy nanoparticles $\cdot$ Silver ion release . Surface plasmon resonance $\cdot$ Sputtered PTFE $\cdot$ PVD $\cdot$ ICP-MS

\section{Introduction}

Bimetallic structures such as alloyed silver and gold nanoparticles have attractive catalytic, electronic, and optical properties that can vary with respect to size and composition of the different metals within the nanostructure [1-3]. Formation of $\mathrm{Ag}-\mathrm{Au}$ alloy structures takes place by mixing them on atomic level without distinct phase boundaries [4]. Due to their plasmonic properties, structural changes upon particle medium interactions in $\mathrm{Ag}$ and $\mathrm{Au}$ nanoparticles can be easily screened. Since their surface plasmon resonance peaks (SPR) are highly sensitive to the particle's size, shape, and surrounding, they can give a lot of information about the status of the nanoparticles [5] and tunable physical properties that can be obtained by changing composition ratio of the alloy nanoparticles [6].

Moreover, the usage of noble metals with silver has shown different silver dissolution behavior. An early study done by Forty examined the oxidation reaction of a bulk silver/gold alloy system in aqueous environment under the phenomena of selective dissolution. Silver is less noble than 
gold and releases easily from the gold alloy system, by leaving a high content of gold residue behind and creating surface vacancies and disordered areas near the surface. When all the surface of alloy is dominated by gold atoms, alloy becomes passivated, and volume and surface diffusions start to play an important role [7].

Recently, several bimetallic/polymer nanocomposites were developed showing promising properties in the silver ion release studies as it has been demonstrated that galvanic coupling of silver with platinum [8-10] or gold [11] strongly increases the silver ion release and its antimicrobial activity.

Barcikowski et al. have examined copper/silver and gold/ silver nanocomposites containing nanoparticles dispersed in a polymer matrix without direct contact generated by laser ablation in liquids. In the $\mathrm{Cu} / \mathrm{Ag}$ system, they found that electrochemical oxidation reaction between the two different metals enhanced the ion release of the less noble $\mathrm{Cu}$ by the ion-mediated electrochemical reaction, and silver ion release was retarded because, when two noble metals with different standard electrochemical potential are in contact with each other in an electrolyte, one of the metals oxidizes or corrodes. This corrosion process is called galvanic corrosion (galvanic coupling), and it enhances the dissolution of the less noble metal atom in alloys, thin films, or sputtered targets. The more noble metal acts as a cathode, and the less noble metal acts as an anode in the electrolyte, thus it provides ion transfer between anode and cathode. Whereas in the case of $\mathrm{Au}-\mathrm{Ag}$ nanocomposite films, no effect on silver ion release was observed due to the absence of mobile gold ions $[12,13]$.

On the other hand, Besner et al. have observed a strong increase in the oxidation resistance with the increase in the $\mathrm{Au}$ fraction inside the $\mathrm{Ag}-\mathrm{Au}$ alloy NPs which could probably result from significant modifications of the electrochemical properties of the NPs. Ag and Au significantly differ in their electronic properties. In this respect, colloidal AgNPs are known to act as an electron storage (donor) medium. Hence, they would easily dissociate through an anodic reaction to release an electron and an $\mathrm{Ag}$ ion. In contrast, $\mathrm{Au}$ is known to possess some electron acceptor properties. The addition of $\mathrm{Au}$ atoms inside the AgNPs would then contribute to the formation of internal electron traps, inhibiting the dissolution of the AgNPs and the release of $\mathrm{Ag}$ ions. Hence, the formation of nanoalloys which exhibit more stability in comparison to $\mathrm{Ag}$ and higher plasmonic response in comparison to $\mathrm{Au}$ could also be beneficial for surface-enhanced Raman scattering applications [14].

We have investigated the silver ion release properties of well-defined model systems consisting of two-dimensional Ag nanoparticle ensembles on top of a polytetrafluoroethylene (PTFE) films which are either directly accessible or covered by polymer layers of well-defined thickness and composition. We observed a correlation between changes in surface plasmon resonance and kinetics of $\mathrm{Ag}$ ion release and that the strong dependence of the silver ion release on the particle size leads to a significant redistribution of the composite morphology and suppression of the Ag ion release rate with time. It was also shown that a polymer barrier stabilizes the morphology of the composites and can be applied to control the Ag ion release rate [15]. Besides, in situ electrochemical impedance spectroscopy-ultravioletvisible spectroscopy (UV-vis) and AFM studies have been also preformed on the same nanocomposite system by our collaborative group indicating the stability of the AgNPs after covering by a PTFE barrier and the slowing of the silver ion release rate [16].

In this work, we report our investigations of silver ion release kinetics from silver-gold alloy nanoparticle ensembles on an insulating hydrophobic polymer substrate and compare these model systems to composites with only pure AgNPs. We examined the changes that occurred after immersing the samples in water for certain time. Twodimensional ensembles of $5.5 \mathrm{~nm}$ nominal thickness consisting of $\mathrm{Ag}-\mathrm{Au}$ alloy NPs of $5 \mathrm{~nm}$ average size were prepared on a highly cross-linked sputtered PTFE substrate using physical vapor deposition (PVD) techniques. The fractions of $\mathrm{Ag}$ and $\mathrm{Au}$ were varied, and the optical properties, composition, and morphology of the nanocomposites were examined using UV-vis, X-ray photoelectron spectroscopy (XPS), and transmission electron microscopy (TEM), respectively. The influence of varying the fraction of the two metals in the alloy NPs on the nanocomposite properties and on the silver ion release rate was also investigated. The timedependent silver ion release was measured by inductively coupled plasma mass spectrometry (ICP-MS). The results show that gold alloying strongly improves the oxidation resistance of the AgNPs. The dissolution of Ag quickly slows down after first exposure to water and reaches a saturation state. No concentration gradient is established upon Ag depletion due to the high atomic mobility in the small NPs.

\section{Experimental}

Preparation of the model system

The 20-nm thin films of PTFE were deposited on quartz $\left(1 \times 1 \mathrm{~cm}^{2}\right)$, silicone $\left(0.5 \times 0.5 \mathrm{~cm}^{2}\right)$, and carbon-coated copper TEM grids by sputtering from a $50 \mathrm{~mm}$ diameter polymer target by RF magnetron source to prevent charging of the target. Preparation of nanocomposites based on sputtering of polymers was reported by the group of Biederman before [17]. The sputtering process of PTFE results in the 
deposition of a highly crosslinked flouropolymer film where surface structure and contact angle determination were shown in our group's previous work of Schürmann et al. [18] and Hassel et al. [19]. The detailed procedure of polymer vapor deposition is described in our previous work [20]. The experiment was done in a homemade stainless steel vacuum chamber, which was initially evacuated to a pressure below $10^{-6} \mathrm{mbar}$. A RF power of $20 \mathrm{~W}$ and a deposition rate of about $4 \mathrm{~nm} / \mathrm{min}$ were used resulting in the deposition of a highly crosslinked flouropolymer film. Later on, samples were mounted in a homemade thermal evaporation chamber and beads of silver (99.99 \%, Sigma Aldrich) and gold (99.99\%, Goodfellow) were loaded into two separated alumina crucibles, and the chamber was evacuated to a pressure below $10^{-6}$ mbar by a vacuum pump system. The $5.5 \mathrm{~nm}$ nominal thickness of $\mathrm{Ag}-\mathrm{Au}$ alloy NPs with various compositions were deposited on top of the polymer film by simultaneous thermal evaporation from the two separated crucibles. The silver evaporator current was increased slowly in order to avoid thermal shocks by raising the voltage $5 \mathrm{mV} / \mathrm{s}$ up to $6.4 \mathrm{~V}$ and a current of 2.2 A with a deposition rate of $0.5 \mathrm{~nm} / \mathrm{min}$. The deposition rate of gold was varied for the different compositions. For $10 \% \mathrm{Au}$ samples, gold evaporator was heated up to $15.8 \mathrm{~V}$ and 3.5 A with a deposition rate of $0.05 \mathrm{~nm} / \mathrm{min}$. For $30 \% \mathrm{Au}$ samples, the evaporator was heated up to $18 \mathrm{~V}$ and 3.7 A with a deposition rate of $0.25 \mathrm{~nm} / \mathrm{min}$, while for $50 \% \mathrm{Au}$ samples the evaporator was heated up to $18.5 \mathrm{~V}$, 3.8 A with a deposition rate of $0.5 \mathrm{~nm} / \mathrm{min}$. A STM-100/ MF quartz crystal microbalance system was used for deposition rate and film thickness monitoring. A DEKTAK 8000 profilometer was used in the calibration of the film thickness with a radius of diamond stylus as $12.5 \mu$ and a stylus tracking force factory, set to $50 \mathrm{mg}$ ).

\section{Characterization}

\section{Transmission electron microscopy (TEM)}

The morphology of the nanocomposites was examined using a Tecnai F30G $^{2}$ ST (FEI) transmission electron microscope operating at $300 \mathrm{kV}$. Samples were prepared on carbon-coated copper grids. The size distribution and average size of the NPs were evaluated by Gatan Digital Micrograph software (by measuring the diameter of each particle in a representative image). Energy-filtered TEM and scanning TEM-HAADF were used to carry out the TEM studies.

\section{$U V$-visible spectroscopy (UV-vis)}

The UV-visible absorption spectra of the prepared nanocomposites on quartz glass were recorded using a PerkinElmer Lambda $900 \mathrm{UV}$-vis/NIR spectrophotometer from 300 to $800 \mathrm{~nm}$ with $2 \mathrm{~nm}$ resolution. A $20 \mathrm{~nm}$ PTFE on quartz sample was used as a reference sample, and all the UV-vis plots are presented in this paper after linear background correction. Due to the small size of the NPs in our model system, the scattering was neglected, and only absorption was considered.

\section{X-ray photoelectron spectroscopy (XPS)}

Films deposited on silicon wafers were used for XPS measurements which were performed by XPS full lab setup from Omicron Nanotechnology $\mathrm{GmbH}$, in its ultra high vacuum analytical chamber where the pressure is usually in $10^{-9}$ mbar range. The analytical chamber consists of sample holder, X-ray source, a hemispherical electron analyzer (VSW EA 125), a detection system which counts the number of photoelectrons, and a data acquisition and processing system. An aluminum anode of the X-ray source (VG Microtech XR3E2) was used here. XPS was used to determine elemental composition of alloy systems taking into account that the information depth is approximately $2 \lambda(2-$ $3 \mathrm{~nm}$ ) where $\lambda$ is the elastic mean free path. More details about using XPS for the study of metal/polymer covering were discussed by Zaporojtchenko et al. [21].

In addition, selected samples were analyzed by XPS with different excitation energies at the PM-4 beamline of the synchrotron facility HZB-BESSY II using the SurICat endstation. Measurements were done with an exit slit of $100 \mu \mathrm{m}$ and with photon energies ranging from 500 to $1,500 \mathrm{eV}$. Spectra were taken in normal electron emission using a hemispherical electron analyzer (Scienta SES 100) operated at a pass energy of $50 \mathrm{eV}$. The spot size on the sample is in the range of $0.5 \mathrm{~mm} \times 0.2 \mathrm{~mm}$. All binding energies and intensities were referenced to a pure gold foil permanently mounted in the vacuum system below the sample holder.

\section{Inductively coupled plasma spectrometry mass (ICP-MS)}

ICP-MS is a sensitive method to detect a wide range of elements with a concentration down to nanograms per liter (ppt; parts per trillion) and below. In this work, an Agilent $7500 \mathrm{cs}$ instrument was used with liquid sample introduction by a PFA micro-nebulizer. Calibration was against aqueous multi-element solutions using indium and rhenium for internal standardization. The procedure detection limit was $10 \mathrm{ng} / \mathrm{l}$ (ppt) Ag. All results are blank-subtracted averages of three replicate measurements. Analytical quality control was monitored by multiple analyses of procedural blanks, unknown samples, and certified reference materials NIST 1643e, IAEA W4. The analytical error for the Ag measurements was $<1 \%$ RSD ( 1 sigma). The actual values for replicate measurements of two samples were 0.4 and $0.8 \%$ RSD, respectively. 
Silver ion release measurements

The Ag ion release rate was studied by observing the changes that occur as samples were immersed in air saturated $10 \mathrm{~mL}$ deionized water $\left(\mathrm{pH}=7, \sigma=0.06 \mu \mathrm{S} / \mathrm{cm}\right.$ at $\left.\mathrm{T}=13^{\circ} \mathrm{C}\right)$ in small bottles made of high-density polyethylene at room temperature. More details about the $\mathrm{pH}$ control can be found in our previous publication [15]. UV-vis and XPS measurements were carried out on the samples during an immersion time of seven days starting from $40 \mathrm{~min}$ to check the variations, and the water was checked by ICP-MS to detect the Ag ions concentrations. Additionally, TEM measurements were done after immersion of the coated TEM grids in water for 3 days.

\section{Results and discussion}

$\mathrm{Au}-\mathrm{Ag}$ alloy NP systems

According to the nucleation and growth model of metal atoms on polymeric surfaces shown in our previous work [22], metal atoms initially adsorb on the polymeric surface until they meet with other atoms on their diffusing paths, and then random or preferred nucleation at defects starts. Initially, the growth of metal nanoparticles on polymeric surface starts by forming small nuclei at certain sites which grow by the continued deposition of the metal via direct impingement and surface diffusion. For alloy NPs, silver and gold were evaporated simultaneously, and a complete alloy formation is expected as gold and silver are in the same group of periodic table and have similar atomic radius and same structures that make them fully miscible in each other in the solid solutions [23]. Figure 1a, b shows a bright field (BF) TEM image for $5.5 \mathrm{~nm}$ of $70 \% \mathrm{Ag}-30 \% \mathrm{Au}$ alloy NPs on PTFE and its corresponding particle size distribution. A uniform distribution could be observed with an average diameter of about $5 \mathrm{~nm}$, except for some largerdiameter particles having irregular shape contribute to coalescence growth of the particles.

The 5.5-nm nominal thickness $\mathrm{Ag}$ and Au alloy nanoparticles have almost a similar size distribution and an average diameter of about $5 \mathrm{~nm}$ as the pure AgNPs prepared in the same way and same amount as was shown in the previous work [15]. The position of the plasmon absorption peak of these alloy NPs, however, depends linearly on the composition of the alloy particles when expressed in terms of the gold fraction as reported previously [2, 14, 24, 25]. The absorption spectra obtained by UV-vis for $5.5 \mathrm{~nm}$ pure $\mathrm{Ag}$ and $\mathrm{Ag}-\mathrm{Au}$ alloy NPs on PTFE with various compositions are shown in Fig. 2. The alloying of $\mathrm{Ag}-\mathrm{Au}$ NPs on PTFE can be concluded from the resulted optical absorption spectra which show a single plasmon resonance peak, whereas two bands would be expected for the case of phase (a)

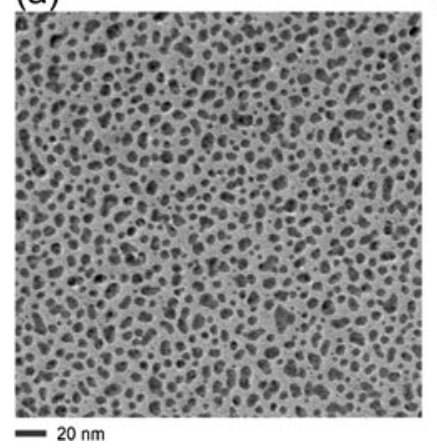

(b)

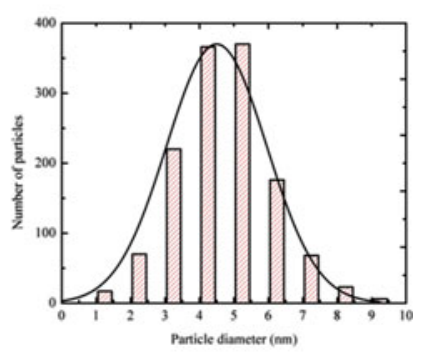

Fig. 1 BF-TEM image (a) and the corresponding particle size distribution (b) of $5.5 \mathrm{~nm} 70 \% \mathrm{Ag}-30 \% \mathrm{Au}$ alloy NPs on PTFE

separated NPs [26, 27]. Alloy formation of $\mathrm{Ag}-\mathrm{Au} \mathrm{NPs}$ caused a plasmon maximum in the UV-vis spectrum between the absorption maximum of $\mathrm{Ag}$ and $\mathrm{Au}$ that varies with respect to composition distribution. The plasmon peak position was red-shifted due to the continuous change of the d-band energy level that contributes to the interband transition term in the dielectric function as a result of an increase in Au composition, and a damping of the absorbance maxima is seen attributed to the higher electron scattering by foreign atoms upon alloying and the gold d-sp interband transition [24, 26, 28].

Silver ion release studies

The Ag ion release kinetics was studied by observing the changes as samples were immersed in water for different time intervals starting from $40 \mathrm{~min}$ up to 7 days. The concentration of the released silver ions from each sample was measured by ICP-MS where results showed a negligible Au ion concentration. Additionally, UV-vis and XPS measurements were

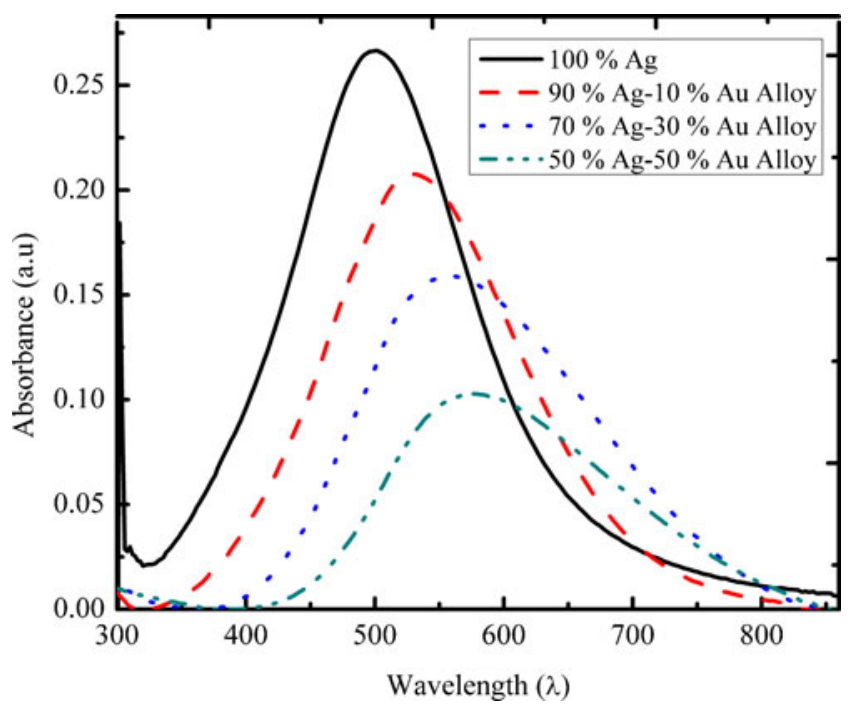

Fig. 2 UV-vis spectra for $5.5 \mathrm{~nm}$ nominal thickness of various composition of $\mathrm{Ag}-\mathrm{Au}$ alloy NPs 


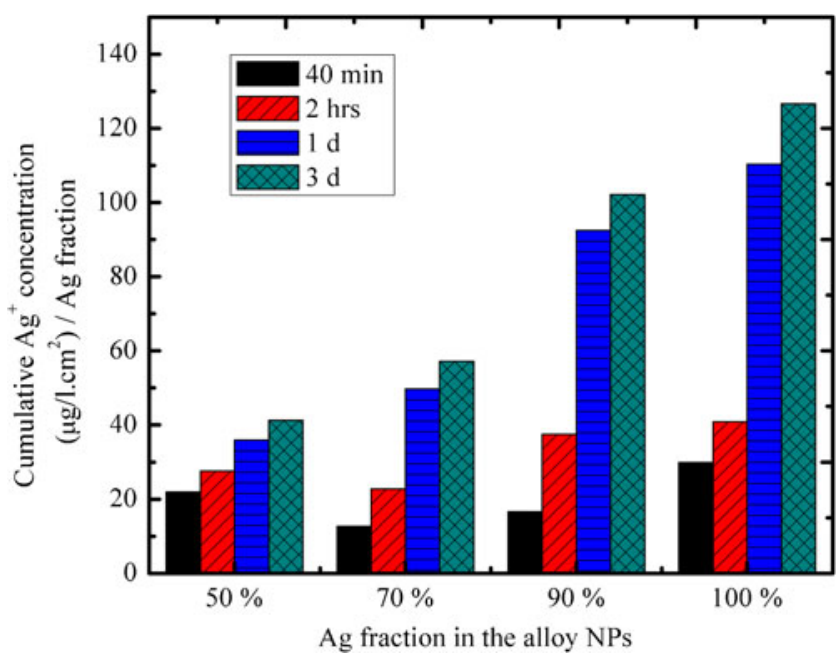

Fig. 3 Cumulative concentration of silver ions released from $\mathrm{Ag}-\mathrm{Au}$ alloy systems at different immersion times in water and different $\mathrm{Ag}$ fraction

carried out for all samples after immersion into aqueous medium. The cumulative concentrations of the released Ag ions (micrograms per liter per square centimeter) normalized to the silver fraction in the alloy nanocomposites were measured at several time periods as shown in Fig. 3. All silver ion concentrations are the mean values of three ICP-MS measurements.

One notices that the release of the silver ions is not just proportional to the amount of silver present in the nanoparticles. In that case, all four diagrams should look the same. But one notes significant differences for short and long release times. In all systems, there was a rapid release of $\mathrm{Ag}$ ions at the beginning (determined after $40 \mathrm{~min}$ ) due to the first interaction of the nanoparticles with water and the Ag dissolution from the surface. The fastest release of the silver is here observed for the pure silver system and the $50 \%$ alloy, while the relative release is smallest for the $70 \%$ alloy system. This can be explained with the entropy of mixing which is most favorable for a $50 \%$ alloy and decreases from there for higher silver fractions [29]. Thus, the initial silver release of the $50 \%$ alloy is not slowed down so much, and the initial release of the $70 \%$ and $90 \%$ alloy is even below the $50 \%$ alloy. But, after 1 day, the relative silver release scales with the amount of silver present, and the pure silver shows the largest silver release, whereas the release is significantly reduced for the alloys. Here, the slowing down of the silver release is directly correlated with the gold fraction in the alloy. The more gold is present in the alloy the more the release is slowed down. For the $90 \%$ alloy system, one observes still a big difference between the release after $2 \mathrm{~h}$ and 1 day, whereas the change for the $50 \%$ alloy system has become already very small. To explain this behavior, one has to consider the change in composition caused by the silver release. For the nanoparticles with initially $90 \%$ silver fraction, the composition will move towards $50 \%$ with a still-higher silver than gold fraction. Here, entropic contributions favor further silver release. The situation is different for the $50 \%$ alloy. Here, the entropic contribution due to change in composition is not favorable for further silver release, and thus, the silver release will be slowed down.

Additionally, increasing the Au fraction inside the NPs could lead to a significant change of the electron transfer properties of the alloy NPs with the composition. This interaction between $\mathrm{Ag}-\mathrm{Au}$ causes depletion and reduces the silver ion release. Thus, a rapid dissolution of $\mathrm{Ag}$ occurred only at the first contact of the sample with water, and when the composition of the alloy NPs becomes Au-rich, a saturation state is approached. This could be an advantage for potential applications where the $\mathrm{Ag}$ ion release is required to be rapid and effective at the beginning then a slower dissolution rate, leading to a continuous release of Ag ions for long-term application.

XPS analysis was also performed to examine changes which occurred for the $70 \% \mathrm{Ag}-30 \% \mathrm{Au}$ alloy NPs on PTFE film deposited on $\mathrm{Si}$ substrate after immersion in water. Intensity of each element and area under the XPS peaks give quantitative information about the elements within the composite. The sensitivity factors of $\mathrm{Ag}$ and $\mathrm{Au}$ are approximately the same [30], so the alloy composition can be determined from the intensity of XPS signal which is the area under the Ag and Au peaks.

Variations in $\mathrm{Ag}$ and $\mathrm{Au}$ peaks intensities were investigated before and after immersion of samples for several days in water. Ag and Au intensities were normalized with respect to the carbon intensity in order to eliminate timedependent changes in the intensity of the XPS spectra, as

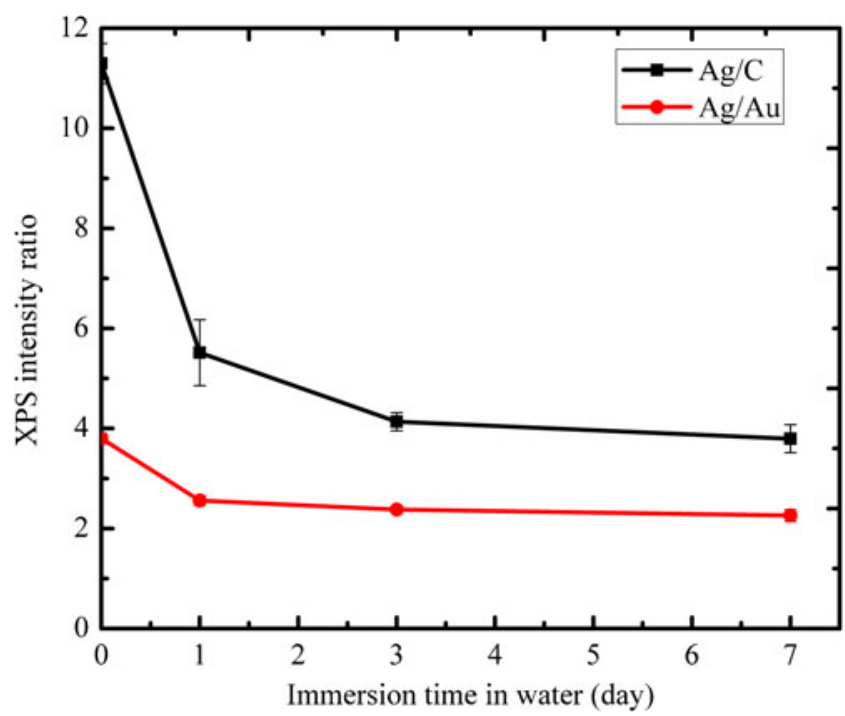

Fig. 4 Change in the XPS Ag and Au intensities for $5.5 \mathrm{~nm} 70 \% \mathrm{Ag}$ $30 \%$ Au alloy NPs on PTFE after immersion in water 
Table 1 Summary of energy-dependent XPS analysis

\begin{tabular}{llll}
\hline $\begin{array}{l}\text { Photon } \\
\text { energy } \\
(\mathrm{eV})\end{array}$ & $\begin{array}{l}\text { Kinetic } \\
\text { energy at Ag } \\
\text { 3d lines (eV) }\end{array}$ & $\begin{array}{l}\text { Inelastic mean } \\
\text { free path } \\
\text { (probing depth) } \\
(\mathrm{nm})^{\mathrm{a}}\end{array}$ & $\begin{array}{l}\text { Decrease of Ag 3d } \\
\text { signal after 3 days } \\
\text { immersion in } \\
\text { water (\%) }\end{array}$ \\
\hline 500 & 130 & $0.43(0.86)$ & $55.3 \pm 3$ \\
650 & 280 & $0.61(1.21)$ & $58.3 \pm 3$ \\
900 & 530 & $0.89(1.78)$ & $53.5 \pm 3$ \\
1,200 & 830 & $1.21(2.41)$ & $52.8 \pm 3$ \\
1,500 & 1,130 & $1.50(3.00)$ & $53.2 \pm 3$ \\
\hline
\end{tabular}

${ }^{a}$ calculated from the data provided by Tanuma et al. assuming a $70 \%$ $\mathrm{Ag}$ and $30 \% \mathrm{Au}$ composition [31]

shown in Fig. 4. Before immersion in water, the ratio of Ag to $\mathrm{Au}$ was a little higher than the expected value. This could be caused by a slightly higher deposition rate of the silver during the co-evaporation of the alloy NPs. Note that, prior to co-evaporation, the deposition rates were calibrated independently, and no cross-influence of the evaporators was taken into account. In addition, the deviation from the expected value could be due to systematic errors in the determination of the peak areas, in particular, for the weaker gold lines.

Due to dissolution of silver after immersion of samples in water, the $\mathrm{Ag} / \mathrm{C}$ and $\mathrm{Ag} / \mathrm{Au}$ intensity ratios decrease rapidly at the beginning, and after the first day, the decrease in the ratios becomes slower with time indicating the approach of a saturation state. One could speculate that this saturation states occurs because silver ions are released only from the outer layers of the nanoparticles and that a gold shell is formed subsequently by the gold that is left behind.

In order to check this possibility, energy-dependent XPS spectra were measured on one set of the $5.5 \mathrm{~nm}$ layer of the $70 \% \mathrm{Ag}-30 \% \mathrm{Au}$ alloy nanoparticles on sputtered PTFE. One sample was measured as prepared and the other one after 3 days of immersion in water. By varying the photon energy, the probing depth is varied (see Table 1). The spectra were analyzed by normalizing the $\mathrm{Au} 4 \mathrm{f}$ lines (at

(a)

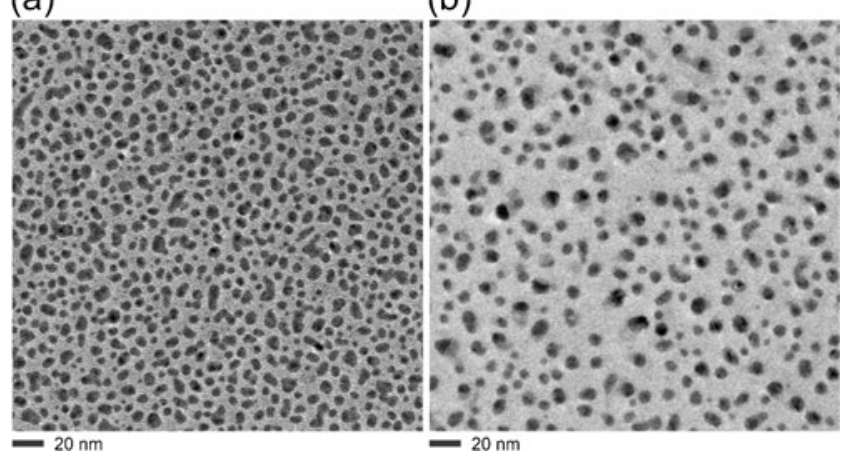

Fig. $55.5 \mathrm{~nm} 70 \% \mathrm{Ag}-30 \% \mathrm{Au}$ alloy NPs on PTFE BF-TEM image before immersion in water (a) and after 3 days in water (b)
84.0 and $87.6 \mathrm{eV}$ ) to the same intensity for all spectra, and then the decrease of the signal of the Ag 3d lines (at 368.3 and $374.2 \mathrm{eV}$ ) due to immersion in water was determined for the different photon energies, i.e., for different probing depths (see Table 1).

The data show no significant variation of the silver depletion with XPS probing depth, indicating that the silver distribution within the nanoparticles remains essentially unchanged, i.e., it remains alloy-like. Therefore, the formation of a gold shell can be ruled out, and the observed slowing down of the silver release of the gold containing alloys must be due to a shift of the chemical potential with increasing gold fraction as has been suggested above and in different words also by Besner et al. [14].

At first glance, this result could appear somewhat surprising since for bulk $\mathrm{Ag}-\mathrm{Au}$ alloy systems the dissolution of silver leads to formation of porous gold structures and for larger nanoparticles by a galvanic exchange reaction indeed hollow nanoparticles with a gold shell can be produced [32]. But as suggested by Shibata et al. [33], the situation is different for smaller nanoparticles, in particular, if they have defects. Here, the vacancies created in the alloy nanoparticles by the released silver atoms should allow a fast redistribution of the silver in a range of several nanometers, thus leading to an always almost homogeneous spatial distribution of the silver in the small nanoparticles.

TEM measurements were also done after 3 days of immersion of the sample deposited on the TEM grid in water. Figure $5 \mathrm{a}, \mathrm{b}$ shows changes in the morphology and in the surface amount of the $5.5 \mathrm{~nm}$ alloy NPs of $70 \% \mathrm{Ag}-30 \%$ $\mathrm{Au}$ before and after immersion in water. The nanoparticles density looks smaller after 3 days in water, and the interparticle distance increases as a result of the reduction of the $\mathrm{Ag}$

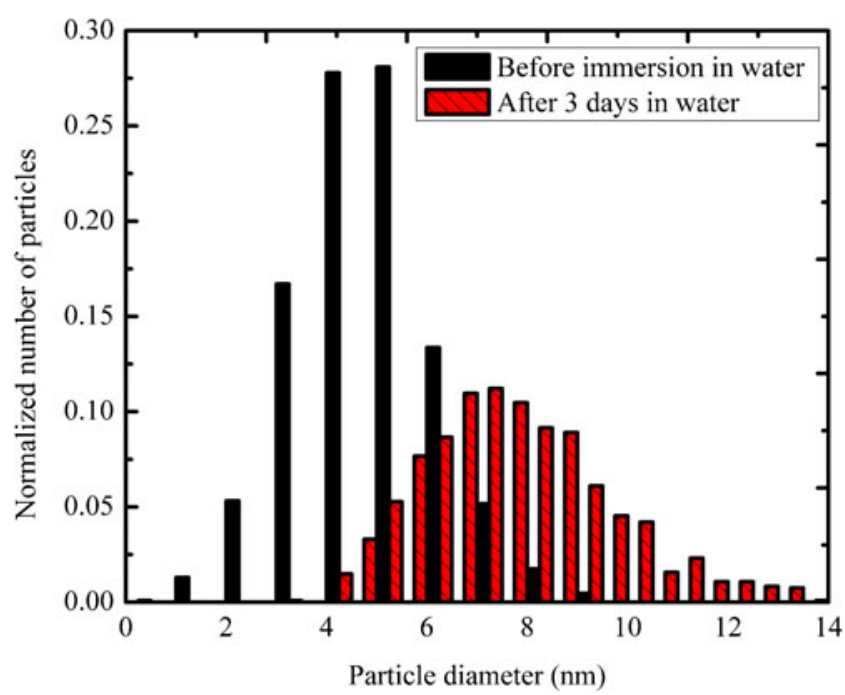

Fig. 6 Particle size distribution of the $5.5 \mathrm{~nm} 70 \% \mathrm{Ag}-30 \% \mathrm{Au}$ alloy NPs on PTFE before and after immersion the TEM grid in water for 3 days 

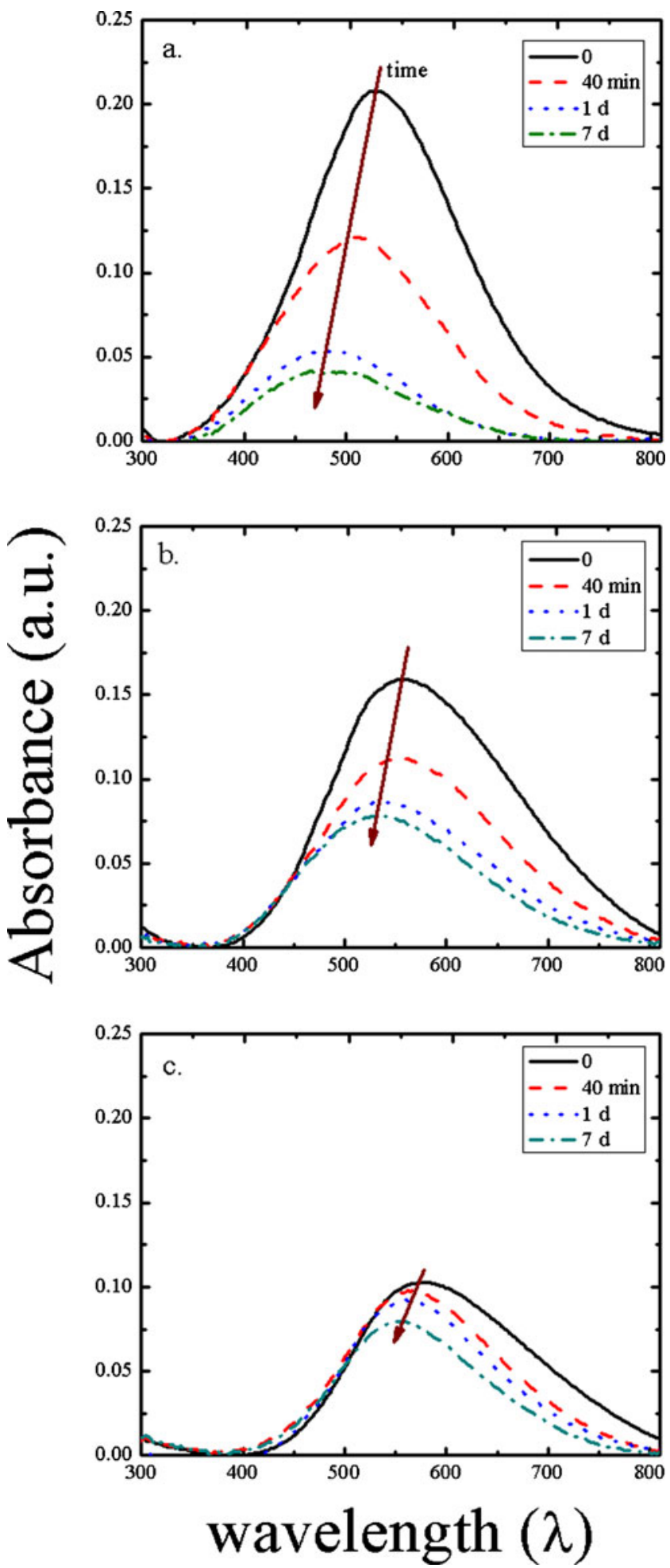

Fig. 7 UV-vis spectra for $5.5 \mathrm{~nm}$ of a $90 \% \mathrm{Ag}-10 \% \mathrm{Au}$; b $70 \% \mathrm{Ag}-$ $30 \% \mathrm{Au}$; and c $50 \% \mathrm{Ag}-50 \%$ Au alloy NPs on PTFE at different immersion times in water

fraction due to $\mathrm{Ag}$ ion release which is more favorable from the smaller particles. Additionally, other NPs may undergo Ostwald ripening process, i.e., growth of large particles by dissolution of small particles driven by the particle size dependence of its standard electrode potential, in a way similar to what we observed before for pure AgNPs [15, 16]. Moreover, no $\mathrm{Au}$ shell formation was observed here either. The change in the particle size distribution is shown in Fig. 6, where the number of particles was normalized to the total number of particles for each case.

Further investigations were performed using the UV-vis technique by observing the changes in the absorbance spectra of $5.5 \mathrm{~nm}$ alloy nanocomposite with various compositions as a function of the immersion time in water; see Fig. 7. After immersion in water, SPR peak positions and absorbance maxima values were changed due to the oxidation and the release of silver ions into aqueous media. The shape of the absorbance peaks for each time period differs from each other too. One expects a red shift towards the typical gold plasmon absorption band due to the increase of the $\mathrm{Au}$ fraction in the nanoalloy [2, 25]. In contrast, a dominant shift to smaller wavelength occurred due to changes in the morphology, size distribution, and the interparticle distance. These changes are similar to the changes that occurred in the pure AgNPs system shown in our previous work [15]. However, the rate of the change in the SPR peak absorbance maxima values and its position after immersion of the samples in water is slower than that for the pure silver due to the increase of the $\mathrm{Au}$ fraction on the expense of $\mathrm{Ag}$ in the alloy, in accordance with the results from the ICPMS and XPS measurements.

\section{Conclusions}

Model systems consisting of two-dimensional ensembles of $5.5 \mathrm{~nm}$ nominal thickness of $\mathrm{Ag}-\mathrm{Au}$ alloy NPs on a $20 \mathrm{~nm}$ highly cross-linked sputtered PTFE substrate were prepared using PVD techniques to investigate the effect of gold alloying on the silver ion release upon immersion in water. Alloying of $\mathrm{Au}$ increases the oxidation resistance of the nanoparticles and results in a reduced absolute release rate. We noticed that the release of the silver ions is proportional to the amount of silver present in the alloy nanoparticles with significant differences for short and long release times. In all systems, a rapid dissolution of Ag occurred only at the first contact of the sample with water, and later on, a saturation state is approached which is also affected by concentration-dependent entropic contributions. XPS and energy-dependent XPS spectra analysis were also performed to examine changes which occurred for the $70 \% \mathrm{Ag}-30 \%$ Au alloy NPs system before and after immersion of samples in water, and results showed that Ag depletion does not lead to a concentration gradient but rather to a homogeneous drop in Ag concentration in the small NPs of about $5 \mathrm{~nm}$ average size investigated. TEM measurements for the same 
alloy system showed changes in the morphology and in the surface amount of the alloy NPs, and no Au shell formation was observed here either. The results suggest that Au alloying can be made instrumental to tailor silver ion release in silver-based nanocomposites.

Acknowledgment We acknowledge the financial support for the initial part of the work by the World Gold Council under project GROW RP 0707. The work was continued by financial support of the German Research Foundation (Deutsche Forschungsgemeinschaft; DFG) under grant number (FA 234/20-1). The authors are grateful for Dipl. Ing. S. Rehders for constructing the deposition chambers and for his expertise in solving technical problems. Many thanks to Dipl. Ing. U. Westernströer for her help in performing the ICP-MS measurements. Moreover, we would like to thank M.Sc. B. Erkartal and Dr. U. Schürmann for TEM measurements. Thanks go also to M. Bauer and Dr. R. Ovsyannikov for support of the XPS synchrotron experiments.

Open Access This article is distributed under the terms of the Creative Commons Attribution License which permits any use, distribution, and reproduction in any medium, provided the original author(s) and the source are credited.

\section{References}

1. Fleger Y, Rosenbluh M (2009) Surface plasmons and surface enhanced Raman spectra of aggregated and alloyed gold-silver nanoparticles. Res lett Opt 2009:1-5

2. Link S, Wang ZL, El-Sayed MA (1999) Alloy formation of goldsilver nanoparticles and the dependence of the plasmon absorption on their composition. J Phys Chem B 103:3529-3533

3. Hubenthal F, Ziegler T, Hendrich C, Alschinger M, Träger F (2005) Tuning the surface plasmon resonance by preparation of gold-core/silver-shell and alloy nanoparticles. Eur Phys J D 34:165-168

4. Zhang Q, Xie J, Lee JY, Zhang J, Boothroyd C (2008) Synthesis of $\mathrm{Ag} @ \mathrm{AgAu}$ metal core/alloy shell bimetallic nanoparticles with tunable shell compositions by a galvanic replacement reaction. Small 4(8):1067-1071

5. Ashby MF, Ferreira Paulo JSG, Schodek-Daniel L (2009) Nanomaterials, nanotechnologies and design. Butterworth-Heinemann, Amsterdam; Boston

6. He ST, Xie SS, Yao JN, Gao HJ, Pang SJ (2002) Self-assembled two-dimensional superlattice of Au-Ag alloy nanocrystals. Appl Phys Lett 81:150-152

7. Forty AJ (1981) Micromorphological studies of the corrosion of gold alloys. Gold Bull 14(1):25-35

8. Dowling DP, Betts AJ, Pope C, McConnell ML, Eloy R, Arnaud MN (2003) Anti-bacterial silver coatings exhibiting enhanced activity through the addition of platinum. Surf Coat Technol 163164:637-640

9. Betts AJ, Dowling DP, McConnell ML, Pope C (2005) The influence of platinum on the performance of silver-platinum antibacterial coatings. Mater Des 26:217-222

10. Kumar R, Howdle S, Münstedt H (2005) Polyamide/silver antimicrobials: effect of filler types on the silver ion release. J Biomed Mater Res 75B(2):311-319

11. Zaporojtchenko V, Podschun R, Schürmann U, Kulkarni A, Faupel F (2006) Physico-chemical and antimicrobial properties of co- sputtered Ag-Au/PTFE nanocomposite coatings. Nanotechnology 17:4904-4908

12. Hahn A, Brandes G, Wagener P, Barcikowski S (2011) Metal ion release kinetics from nanoparticle silicone composites. J Controlled Release 154:164-170

13. Hahn A, Günther S, Wagener P, Barcikowski S (2011) Electrochemistrycontrolled metal ion release from silicone elastomer nanocomposites through combination of different metal nanoparticles. J Mater Chem 21:10287-10289

14. Besner S, Meunier M (2010) Femtosecond laser synthesis of AuAg nanoalloys: photoinduced oxidation and ions release. J Phys Chem C 114:10403-10409

15. Alissawi N, Zaporojtchenko V, Strunskus T, Hrkac T, Kocabas I, Erkartal B, Chakravadhanula VSK, Kienle L, Grundmeier G, Garbe-Schönberg D, Faupel F (2012) Tuning of the ion release properties of silver nanoparticles buried under a hydrophobic polymer barrier. J Nanopart Res 14:928-939

16. Yliniemia K, Ozkaya B, Alissawi N, Zaporojtchenko V, Strunskus T, Wilson BP, Faupel F, Grundmeier G (2012) Combined in situ electrochemical impedance spectroscopy-UV/Vis and AFM studies of Ag nanoparticle stability in perfluorinated films. Mater Chem Phys 134:302-308

17. Biederman H (2000) RF sputtering of polymers and its potential application. Vacuum 59:594-599

18. Schürmann U, Hartung W, Takele H, Zaporojtchenko V, Faupel F (2005) Controlled syntheses of Ag-PTFE nanocomposite thin films by co-sputtering from two magnetron sources. Nanotechnology 16:1078-1082

19. Hassel AW, Milenkovic S, Schürmann U, Greve H, Zaporojtchenko V, Adelung R, Faupel F (2007) Model systems with extreme aspect ratio, tunable geometry, and surface functionality for a quantitative investigation of the lotus effect. Langmuir 23:2091-2094

20. Faupel F, Zaporojtchenko V, Greve H, Schürmann U, Chakravadhanula VSK, Hanisch C, Kulkarni A, Gerber A, Quandt E, Podschun R (2007) Deposition of nanocomposites by plasmas. Contrib Plasma Phys 47(7):537-544

21. Zaporojtchenko V, Behnke K, Strunskus T, Faupel F (2000) Condensation coefficients of noble metals on polymers: a novel method of determination by X-ray photoelectron spectroscopy. Surf Interface Anal 30:439-443

22. Zaporojtchenko V, Strunskus T, Behnke K, Von Bechtolsheim C, Kiene M, Faupel F (2000) Metal/polymer interfaces with designed morphologies. J Adhesion Sci Technol 14:467-490

23. Palanna OG (2009) Engineering chemistry. Tata McGraw-Hill Education Pvt. Ltd., New Delhi

24. Chen DH, Chen CJ (2002) Formation and characterization of AuAg bimetallic nanoparticles in water-in-oil microemulsions. J Mater Chem 12:1557-1562

25. Beyene HT, Chakravadhanula VSK, Hanisch C, Elbahri M, Strunskus T, Zaporojtchenko V, Kienle L, Faupel F (2010) Preparation and plasmonic properties of polymer-based composites containing Ag$\mathrm{Au}$ alloy nanoparticles produced by vapor phase co-deposition. $\mathrm{J}$ Mater Sci 45:5865-5871

26. Kreibig U, Vollmer M (1995) Optical properties of metal clusters. Springer series in Material Sciences, vol 25. Springer, Berlin

27. Chen Y, Wu H, Li Z, Wang P, Yang L, Fang Y (2012) The study of surface plasmon in $\mathrm{Au} / \mathrm{Ag}$ core/shell compound nanoparticles. Plasmonics. doi:10.1007/s11468-012-9336-6

28. Feng L, Gao G, Huang P, Wang K, Wang X, Luo T, Zhang C (2010) Optical properties and catalytic activity of bimetallic goldsilver nanoparticles. Nano Biomed Eng 2(4):258-267

29. Haasen P (1996) Physical metallurgy. Translated by Janet Mordike; Cambridge: Cambridge University Press, 3rd ed 
30. Moulder F, Stickle WF, Sobol PE, Bomben K (1992) Handbook of X-ray photoelectron spectroscopy. Prairie, MN: Perkin-Elmer Corporation, 2nd ed

31. Tanuma S, Shiratori T, Kimura T, Goto K, Ichimura S, Powell CJ (2005) Experimental determination of electron inelastic mean free paths in 13 elemental solids in the 50 to $5000 \mathrm{eV}$ energy range by elastic-peak electron spectroscopy. Surf Interface Anal 37:833-845
32. Petri MV, Ando RA, Camargo PHC (2012) Tailoring the structure, composition, optical properties and catalytic activity of Ag-Au nanoparticles by the galvanic replacement reaction. Chem Phys Lett 531:188-192

33. Shibata T, Bunker BA, Zhang Z, Meisel D, Vardeman CF II, Gezelter JD (2002) Size-dependent spontaneous alloying of AuAg nanoparticles. J Am Chem Soc 124(40):11989-11996 